\title{
Extraction of Saponin from Camellia oleifera Abel Cake by a Combination Method of Alkali Solution and Acid Isolation
}

\author{
Yongjun Liu, Zhifeng Li, Hongbo Xu, and Yuanyuan Han \\ College of Chemical Engineering, Huaqiao University, Xiamen 361021, China \\ Correspondence should be addressed to Yongjun Liu; yongjunliu@hqu.edu.cn and Yuanyuan Han; hanyuan@hqu.edu.cn
}

Received 4 November 2015; Revised 4 January 2016; Accepted 14 January 2016

Academic Editor: Ana Moldes

Copyright (C) 2016 Yongjun Liu et al. This is an open access article distributed under the Creative Commons Attribution License, which permits unrestricted use, distribution, and reproduction in any medium, provided the original work is properly cited.

Saponin 15\% 20\% content in the seed cake of Camellia oleifera Abel, from which Camellia oil is squeezed, is a natural nonionic surface active agent and is extensively applied to emulsification, humectation, foaming, medicine, pesticide, and so on. In this paper, the extraction process of saponin was researched through a combining method of alkali solution and acid isolation. A quantitative method for saponin was established by ultraviolet spectrophotometer. The influence of extraction factors was investigated by a single-factor test and a response surface methodology. The results indicated that the optimal extraction conditions of saponin were extraction temperature $68^{\circ} \mathrm{C}$, alkali solution $\mathrm{pH}$ 9.1, acid isolation $\mathrm{pH}$ 4.1, and liquid-solid ratio $15.9: 1$. The extraction rate of saponin was $76.12 \%$ at the optimal extraction conditions.

\section{Introduction}

There are about 5 million hectares of Camellia oleifera Abel forests in China. About 202 million tons of mature oil seed, 40 million tons of Camellia oleifera Abel oil, and 162 million tons of seed cake meal can be produced annually [1]. At present, China is the largest country producing Camellia oleifera Abel seed in the world. Saponin, the most important content in seed cake of Camellia oleifera Abel, about 15\% to $20 \%$, is a natural nonionic surfactant and exhibits good performance in emulsification, foaming, dispersing, lubrication, and decontamination. Therefore, it can be extensively applied to chemical industry, building materials, agriculture, aquaculture, pharmaceutical and healthcare industries, and so forth [1-5]. However, most of these seed cakes have long been thrown away as rubbish in China, which results in a waste of saponin resources.

Many extraction methods for saponin from Camellia cake, for example, conventional water extraction, ethanol extraction processes, and some novel techniques (such as absolute ethyl alcohol method, supercritical $\mathrm{CO}_{2}$ extraction method, and ultrasonic solubilization method) [6-13], have been extensively studied over the recent decades. However, water extraction process has problems of high-energy consumption, large evaporation, difficult separation of extracts and low quality of saponin. Conventional ethanol extraction process has problems of high consumption of solvent, long extraction time, and complex equipment as well as high cost of production.

Alkali solution and acid isolation method is a technique for separation and purification by utilizing the acid-alkali difference of components in a mixture, applied to extracting the proteins, flavonoids, and other substances [14, 15]. Alkali solution and acid isolation method can effectively improve extraction rate of the desired product. It also has advantages in investment, handiness of operation, environmental pollution, nonsolvent extraction, and so forth. However, there is few published literature on the application of the alkali solution and acid isolation method to produce saponin from the seed cake of Camellia oleifera Abel.

The extraction of saponin by alkali solution and acid isolation method can possibly be described as follows: saponin from Camellia oleifera cake is a kind of triterpenoid saponin consisting of a fat-soluble pentacyclic triterpenoid unit and a water-soluble sugar unit via carbon-oxygen bond. Some acidic ingredients in saponin (e.g., tannin) can be completely dissolved in a dilute alkali solution. Subsequently, hydrochloric acid is dropwise added to the alkali solution extract to a certain $\mathrm{pH}$ value. The saponin with a liposoluble pentacyclic triterpenoid unit will be precipitated from the high polarity 


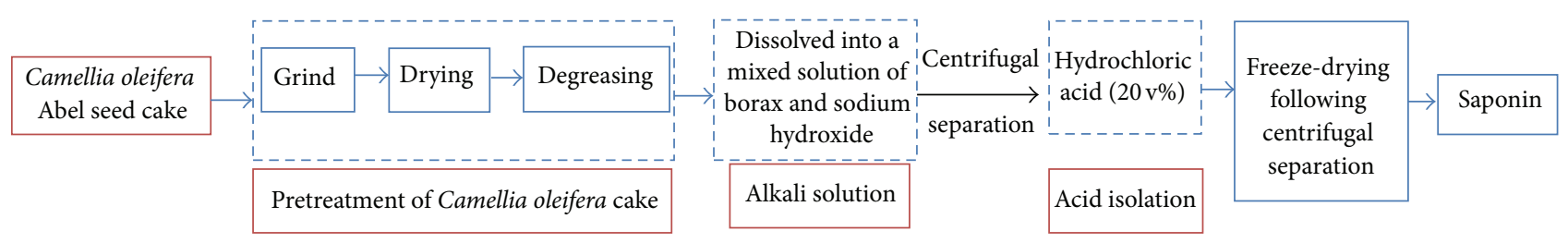

FIGURE 1: The flowchart of the extraction process of saponin.

acid solution. In the present work, the extraction process of saponin is investigated by means of combining method of alkali solution and acid isolation. A quantitative method for saponin was established by ultraviolet spectrophotometer. The effects of the extraction factors were examined by a single-factor test and a response surface methodology, in order to achieve optimal extraction conditions of saponin from the seed cake of Camellia oleifera Abel.

\section{Experiment and Method}

2.1. Extraction Process of Saponin. A typical extraction process of saponin from Camellia cake (after squeezing oil, derived from Fujian Huaren Oil-Grease Company) mainly includes the following 3 steps. (1) Pretreatment of Camellia oleifera cake: the cake was crushed by a grinder and sieved to less than $0.150 \mathrm{~mm}$ and then dried for $12 \mathrm{~h}$ at $105^{\circ} \mathrm{C}$. The oil in the fine cakes was extracted for $2 \mathrm{~h}$ at $80^{\circ} \mathrm{C}$ by petroleum ether in a Soxhlet extractor. Meanwhile, 10 15\% Camellia oil could be gained from the extract liquor. The deoiled cakes were dried at $105^{\circ} \mathrm{C}$ to achieve constant weight. (2) Alkali solution: the prepared cakes were dissolved into a mixed solution of borax and sodium hydroxide and then heated and stirred for some time, following a centrifugal separation in order to remove solid impurities. (3) Acid isolation: hydrochloric acid (20 v\%) was dropwise added to the centrifugal liquor to achieve a certain $\mathrm{pH}$ value. White precipitate was separated out immediately. After freeze-drying and centrifugal separation, the yellowish-brown saponin could be obtained. The flowchart of the extraction process of saponin is shown in Figure 1.

2.2. UV Analysis of Saponin after Colorimetric Reaction by Vanillic Aldehyde and Concentrated Sulfuric Acid. The blend of vanillin and concentrated sulfuric acid can be utilized to react with saponin to produce red solution, which is considered as a typical colorimetric method in order to quantify the amount of saponin. Therefore, we determined the content of saponin extracted by colorimetric reaction using vanillic aldehyde and concentrated sulfuric acid. A typical procedure is described as follows: $0.5 \mathrm{~mL}$ standard solution of saponin was placed into a test tube with a stopper. $0.5 \mathrm{~mL}$ of vanillin dissolved in absolute ethanol $(8 \% \mathrm{w} / \mathrm{v})$ was then added to the tube cooling in ice water. $4 \mathrm{~mL}$ of $77 \mathrm{v} \%$ sulfuric acid was dropwise added to the foregoing solution and shaken well. The tube was heated for $15 \mathrm{~min}$ at $60^{\circ} \mathrm{C}$ and then cooled. A UV spectrophotometer was employed to measure the absorbance of prepared solution for quantitative analysis, at $547 \mathrm{~nm}$ of the maximum absorption wavelength.
2.3. Establishment of Standard Curve. Different volumes (0, $0.1,0.2,0.3,0.4,0.5,0.6,0.7,0.8,0.9$, and $1.0 \mathrm{~mL}$ ) of the stock standard solutions of saponin were transferred into a test tube with a stopper and diluted with water to a metered volume $(1.0 \mathrm{~mL})$, respectively. After colorimetric reaction of saponin as stated above, absorbance of prepared solution at the maximum absorption wavelength was measured by UV spectrophotometer. The linear relationship of absorbance and saponin content could be then obtained by regression analysis:

$$
Y=0.8232 X+0.0055
$$

where $Y$ is the absorbance of prepared solution at $547 \mathrm{~nm}$ and $X$ is the mass concentration of saponin (\%). The correlation coefficient $\left(R^{2}\right)$ is 0.9967 .

The saponin content of crude Camellia oleifera cake is $18.9 \mathrm{w} \%$, measured by this standard curve.

2.4. Experimental Design. Firstly, a series of single-factor experiments, such as liquid-solid ratio (Camellia oleifera cake/alkali liquor, w/v), alkali solution $\mathrm{pH}$, extraction temperature, extraction time, and acid isolation $\mathrm{pH}$, were carried out to evaluate the effects of these factors on saponin extraction. Then, a three-level, four-factor Box-Behnken design [16] (response surface methodology) was employed for optimizing the process. The extraction rate of saponin (extraction quality of saponin from sample/original quality of saponin in sample $\times 100 \%$ ) was used as the indices in evaluating the results of extraction. The independent factors and levels of experimental design with observed values for the response are given in Tables 1 and 2. The factors and levels studied in obtaining saponin were determined on the basis of factorial experiments, such as liquid-solid ratio, alkali solution $\mathrm{pH}$, extraction temperature, and acid isolation $\mathrm{pH}$.

\section{Results and Discussion}

\subsection{Single-Factor Experiments}

3.1.1. Effect of Liquid-Solid Ratio on Saponin Extraction. The influence of liquid-solid ratio on saponin extraction was carried out at alkali solution $\mathrm{pH} 10$, extraction temperature $60^{\circ} \mathrm{C}$, extraction time $60 \mathrm{~min}$, and acid precipitation $\mathrm{pH}$ 3. The result is shown in Figure 2. The extraction rate of saponin went up from $31.8 \%$ to $55.9 \%$ with liquid-solid ratio increased from $5: 1$ to $15: 1$, respectively. However, when liquid-solid ratio was more than $15: 1$, the saponin extraction rate decreased slightly and became stable. Besides 
TABLE 1: Levels and factors of response surface analysis for extracting saponin from Camellia oleifera cake.

\begin{tabular}{lcccc}
\hline & & \multicolumn{2}{c}{ Factor } & \\
Level & $A$ & $B$ & $C$ & $D$ \\
& Extraction temperature $/{ }^{\circ} \mathrm{C}$ & Alkali solution $\mathrm{pH}$ & Acid isolation pH & $10: 1$ \\
\hline 1 & 60 & 8 & 3 & $15: 1$ \\
0 & 70 & 9 & 4 & $20: 1$ \\
-1 & 80 & 10 & 5 & Liquid-solid ratio (mL/g) \\
\hline
\end{tabular}

TABLE 2: The design and experimental results of response surface analysis for extracting saponin from Camellia oleifera cake.

\begin{tabular}{|c|c|c|c|c|c|}
\hline Number & $\begin{array}{c}A \\
\text { Extraction temperature } /{ }^{\circ} \mathrm{C}\end{array}$ & $\begin{array}{c}B \\
\text { Alkali solution } \mathrm{pH}\end{array}$ & $\begin{array}{c}C \\
\text { Acid isolation } \mathrm{pH}\end{array}$ & $\begin{array}{c}D \\
\text { Liquid-solid ratio }(\mathrm{mL} / \mathrm{g})\end{array}$ & $\begin{array}{c}Y \\
\text { Extraction rate of saponin/\% }\end{array}$ \\
\hline 1 & 80 & 9 & 5 & $15: 1$ & 60.431 \\
\hline 2 & 70 & 9 & 3 & $10: 1$ & 53.021 \\
\hline 3 & 60 & 9 & 5 & $15: 1$ & 67.431 \\
\hline 4 & 80 & 8 & 4 & $15: 1$ & 59.436 \\
\hline 5 & 70 & 9 & 4 & $15: 1$ & 73.721 \\
\hline 6 & 60 & 9 & 4 & $10: 1$ & 61.757 \\
\hline 7 & 80 & 9 & 4 & $20: 1$ & 61.133 \\
\hline 8 & 60 & 9 & 3 & $15: 1$ & 60.782 \\
\hline 9 & 80 & 9 & 4 & $10: 1$ & 59.456 \\
\hline 10 & 80 & 10 & 4 & $15: 1$ & 61.874 \\
\hline 11 & 70 & 10 & 4 & $20: 1$ & 63.083 \\
\hline 12 & 70 & 8 & 5 & $15: 1$ & 61.269 \\
\hline 13 & 60 & 8 & 4 & $15: 1$ & 57.759 \\
\hline 14 & 60 & 10 & 4 & $15: 1$ & 65.520 \\
\hline 15 & 70 & 10 & 3 & $15: 1$ & 57.467 \\
\hline 16 & 70 & 9 & 5 & $20: 1$ & 61.757 \\
\hline 17 & 80 & 9 & 3 & $15: 1$ & 58.832 \\
\hline 18 & 70 & 9 & 4 & $15: 1$ & 74.379 \\
\hline 19 & 70 & 9 & 3 & $20: 1$ & 60.899 \\
\hline 20 & 70 & 8 & 4 & $10: 1$ & 52.299 \\
\hline 21 & 70 & 9 & 4 & $15: 1$ & 75.936 \\
\hline 22 & 70 & 8 & 3 & $15: 1$ & 51.558 \\
\hline 23 & 70 & 9 & 4 & $15: 1$ & 75.211 \\
\hline 24 & 60 & 9 & 4 & $20: 1$ & 68.055 \\
\hline 25 & 70 & 8 & 4 & $20: 1$ & 61.016 \\
\hline 26 & 70 & 9 & 4 & $15: 1$ & 76.398 \\
\hline 27 & 70 & 9 & 5 & $10: 1$ & 58.247 \\
\hline 28 & 70 & 10 & 5 & $15: 1$ & 59.924 \\
\hline 29 & 70 & 10 & 4 & $10: 1$ & 58.247 \\
\hline
\end{tabular}

that, excess extraction solvent could lead to the difficulty in saponin concentration after extraction. Therefore, the appropriate ratio of liquid to solid $(\mathrm{mL} / \mathrm{g})$ is around $15: 1$.

3.1.2. Effect of Alkali Solution pH Value on Saponin Extraction. Figure 3 shows the influence of alkali solution $\mathrm{pH}$ value on saponin extraction, carried out under similar conditions as mentioned in Section 3.1.1. The fat-soluble pentacyclic triterpenoid unit in saponin cannot be dissolved in a solution with too low alkali solution $\mathrm{pH}$ value but may be destroyed with too high $\mathrm{pH}$ value. From Figure 3, it can be seen that the appropriate alkali solution $\mathrm{pH}$ value is from 9 to 11 . Meanwhile, we detected more impurities in a higher $\mathrm{pH}$ value solution. Therefore, the appropriate alkali solution $\mathrm{pH}$ value should be around 9 .

\subsubsection{Effects of Extraction Temperature and Extraction Time on} Saponin Extraction. The influence of extraction temperature on saponin extraction was shown in Figure 4. It is obvious that the most optimal extraction temperature is around $70^{\circ} \mathrm{C}$. Saponin was not apt to dissolve in the solution under a low extraction temperature, while some structures of saponin might be destroyed at a high extraction temperature. 
TABLE 3: The ANOVA of extraction rate of tea saponin extracted from oil-tea cake.

\begin{tabular}{|c|c|c|c|c|c|c|}
\hline Source of variation & Sum of squares & Degree of freedom & Mean square & $F$ value & $P$ value & Significance \\
\hline Model & 1292.67 & 14 & 92.33 & 48.18 & $<0.0001$ & $* *$ \\
\hline$A$ & 33.81 & 1 & 33.81 & 17.64 & 0.0009 & $* *$ \\
\hline$B$ & 43.23 & 1 & 43.23 & 22.56 & 0.0003 & $* *$ \\
\hline C & 58.52 & 1 & 58.52 & 30.54 & $<0.0001$ & $* *$ \\
\hline$D$ & 90.29 & 1 & 90.29 & 47.11 & $<0.0001$ & $* *$ \\
\hline$A B$ & 7.08 & 1 & 7.08 & 3.7 & 0.0751 & \\
\hline$A C$ & 6.38 & 1 & 6.38 & 3.33 & 0.0896 & \\
\hline$A D$ & 5.34 & 1 & 5.34 & 2.79 & 0.1173 & \\
\hline$B C$ & 13.16 & 1 & 13.16 & 6.86 & 0.0202 & $*$ \\
\hline$B D$ & 3.76 & 1 & 3.76 & 1.96 & 0.1828 & \\
\hline$C D$ & 4.77 & 1 & 4.77 & 2.49 & 0.137 & \\
\hline$A^{2}$ & 149.98 & 1 & 149.98 & 78.25 & $<0.0001$ & $* *$ \\
\hline$B^{2}$ & 517.86 & 1 & 517.86 & 270.21 & $<0.0001$ & $* *$ \\
\hline$C^{2}$ & 486.97 & 1 & 486.97 & 254.09 & $<0.0001$ & $* *$ \\
\hline$D^{2}$ & 389.16 & 1 & 389.16 & 203.05 & $<0.0001$ & $* *$ \\
\hline Residual error & 26.83 & 14 & 1.92 & & & \\
\hline Lack of fit & 22.02 & 10 & 2.2 & 1.83 & 0.2941 & Not significant \\
\hline Pure error & 4.81 & 4 & 1.2 & & & \\
\hline Total & 1319.5 & 28 & & & & \\
\hline
\end{tabular}

${ }^{*}$ Significant; ${ }^{* *}$ very significant.

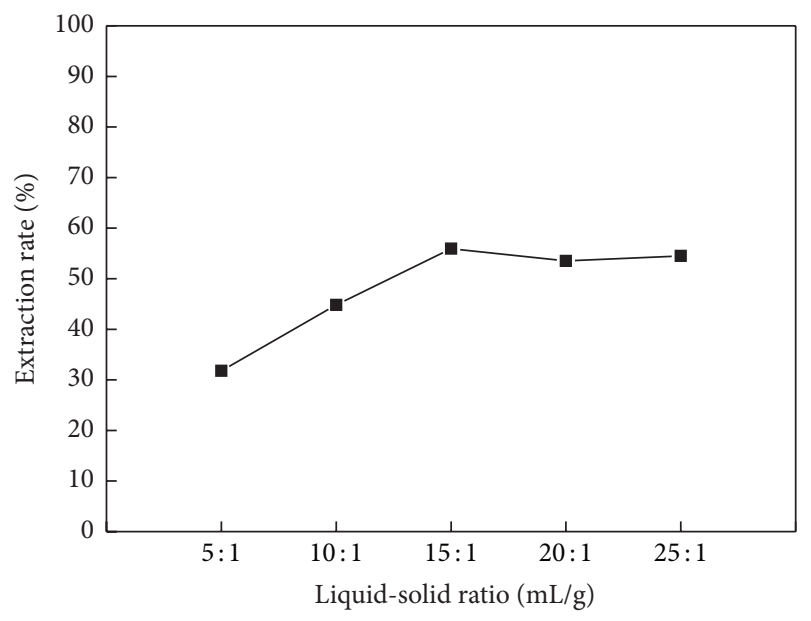

FIGURE 2: Effect of liquid-solid ratio on the extraction rate of saponin (alkali solution $\mathrm{pH}$ value $10 \mathrm{~mL} / \mathrm{g}$, extraction temperature $60^{\circ} \mathrm{C}$, extraction time $60 \mathrm{~min}$, and acid isolation $\mathrm{pH}$ value 3 ).

The extraction rate of saponin revealed a general uptrend with extraction time extended, illustrated in Figure 5. However, the extraction rate tended to be stable after $90 \mathrm{~min}$. Although the content of saponin in extraction solvent rose when extraction time was increased too much, the mass transfer force between saponin in Camellia cake and solvent was decreased, and the extraction system even was brought into dynamic equilibrium. So, a long extraction time will lead to the decline of extracting efficiency of saponin and a high cost.

3.1.4. Effect of Acid Isolation pH Value on Saponin Extraction. Figure 6 indicates the influence of acid isolation $\mathrm{pH}$ value on saponin extraction. The extraction rate of saponin was distinctly up from $23.5 \%$ to $66.2 \%$ when the acid isolation $\mathrm{pH}$ value was increased from 1 to 4 . Saponin may partially hydrolyze or redissolve in the solution with high acidity. Meanwhile, when the $\mathrm{pH}$ value of the solution was too high (e.g., more than 5), saponin may be difficult to precipitate from the mother solution. Thus, the appropriate acid isolation $\mathrm{pH}$ value is around 4 .

3.2. Analysis of Response Surface. Response surface methodology used in this study is an efficient statistical technique for modeling and optimization of multiple variables to predict the best conditions with a minimum number of experiments [17].

The levels of saponin extraction rate in extracted substance from the twenty-nine sets of variable combinations (Table 2) were fit into a quadratic regression equation by using the software Design-Expert 8.0. The estimated values of constant coefficients and analysis of variance were shown in Table 3, and the regression model for saponin extraction rate $(Y)$ was predicted as follows:

$$
\begin{aligned}
Y= & 75.13-1.68 \times A+1.90 \times B+2.21 \times C+2.74 \\
& \times D-1.33 \times A \times B-1.26 \times A \times C-1.16 \times A \\
& \times D-1.81 \times B \times C-0.97 \times B \times D-1.09 \times C \\
& \times D-4.81 \times A^{2}-8.94 \times B^{2}-8.66 \times C^{2}-7.75 \\
& \times D^{2},
\end{aligned}
$$

where $A$ is the extraction temperature, $B$ is the alkali solution $\mathrm{pH}, \mathrm{C}$ is the acid isolation $\mathrm{pH}$, and $D$ is the liquid-solid ratio.

$P$ values determine the significance of each coefficient, and a higher significance of the corresponding coefficient is 


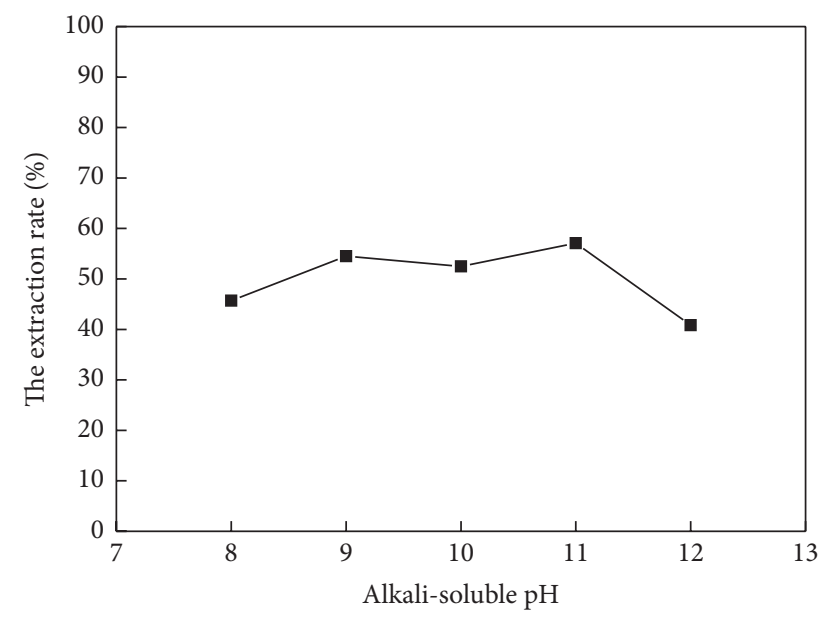

Figure 3: Effect of alkali solution $\mathrm{pH}$ value on the extraction rate of saponin (liquid-solid ratio $10 \mathrm{~mL} / \mathrm{g}$, extraction temperature $60^{\circ} \mathrm{C}$, extraction time $60 \mathrm{~min}$, and acid isolation $\mathrm{pH}$ value 3 ).

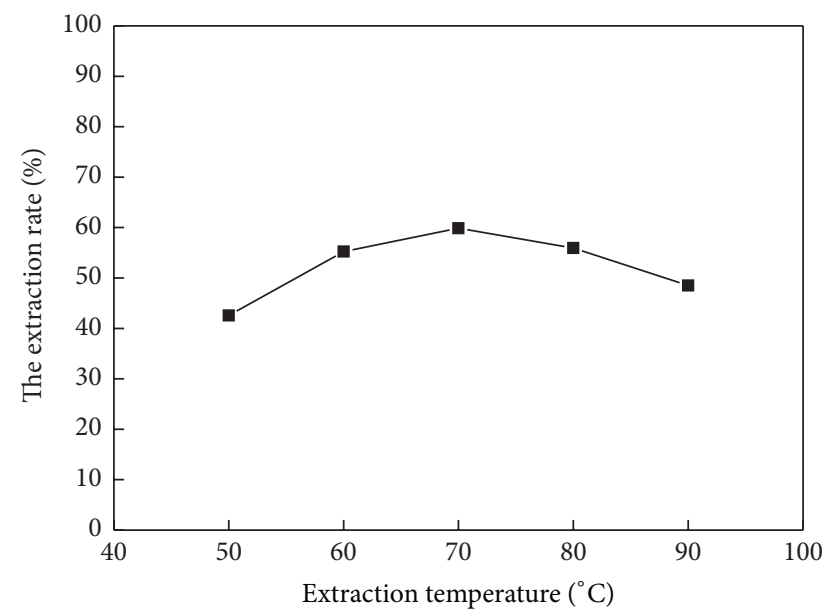

FIGURE 4: Effects of extraction temperature on the extraction rate of saponin (liquid-solid ratio $10 \mathrm{~mL} / \mathrm{g}$, alkali solution $\mathrm{pH}$ value 10 , extraction time $60 \mathrm{~min}$, and acid isolation $\mathrm{pH}$ value 3 ).

indicated by a lower $P$ value [18]. In Table 3 , the $P$ values from model, $A, B, C$, and $D$ items were less than 0.001 . It can be stated that the predicted model was extremely significant. Meanwhile, the order of effects of different factors on saponin extraction rate was liquid-solid ratio $>$ acid isolation $\mathrm{pH}>$ alkali solution $\mathrm{pH}>$ extraction temperature, suggesting that they were significant for the optimization of extraction of saponin from Camellia oleifera cake. Analysis of model reliability in Table 4 showed that high $R$-squared (0.9797, close to 1.0$)$, low coefficient of variation $(2.21 \%)$, and similarity of adjusted $R$-squared and predicted $R$-squared indicated the high reliability of this model.

The response surface plots based on the model were shown in Figures 7(a)-7(f). Figure 7(a) showed the relationship between extraction temperature and alkali solution $\mathrm{pH}$ value, holding another two variables constant (liquidsolid ratio $=15.0 \mathrm{~mL} / \mathrm{g}$, alkali solution $\mathrm{pH}$ value $=4.0$ ). As extraction temperature (e.g., alkali solution $\mathrm{pH}$ value $=8$ ) or
TABLE 4: Analysis of model reliability.

\begin{tabular}{lc}
\hline Item & Value \\
\hline Standard deviation & 1.38 \\
Mean & 62.65 \\
Coefficient of variation (\%) & 2.21 \\
PRESS & 134.35 \\
$R$-squared & 0.9797 \\
Adjusted $R$-squared & 0.9593 \\
Predicted $R$-squared & 0.8982 \\
Adeq. precision & 23.622 \\
\hline
\end{tabular}

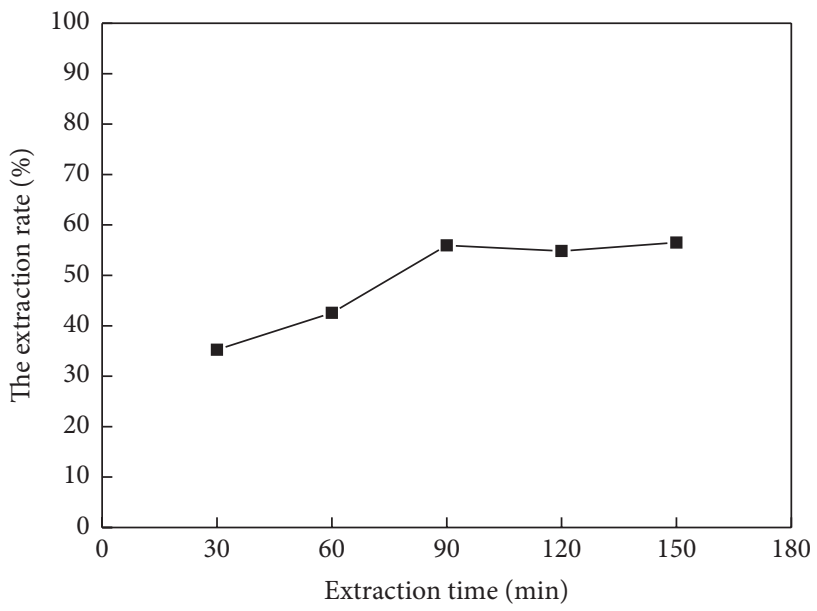

FIGURE 5: Effects of extraction time on the extraction rate of saponin (liquid-solid ratio $10 \mathrm{~mL} / \mathrm{g}$, alkali solution $\mathrm{pH}$ value 10 , extraction temperature $60^{\circ} \mathrm{C}$, and acid isolation $\mathrm{pH}$ value 3 ).

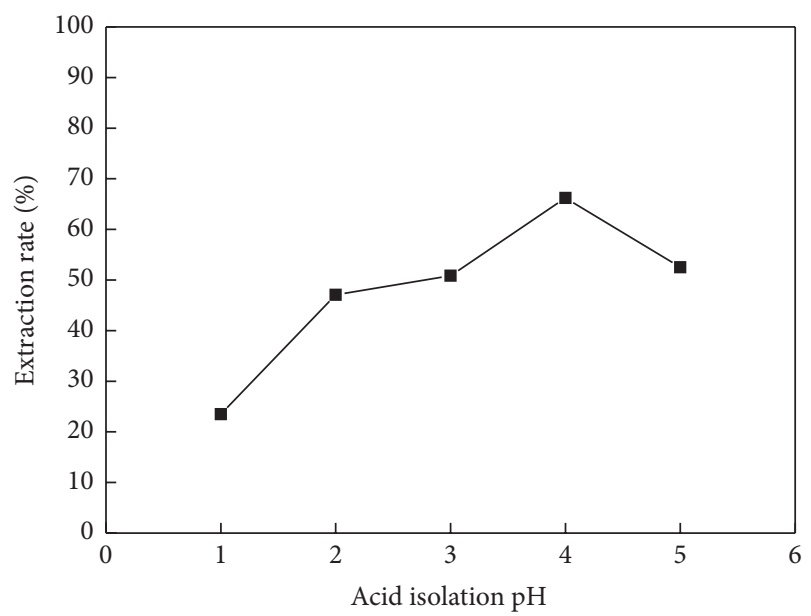

FIGURE 6: Effect of acid solution $\mathrm{pH}$ value on the extraction rate of saponin (liquid-solid ratio $10 \mathrm{~mL} / \mathrm{g}$, alkali solution $\mathrm{pH}$ value 10 , extraction temperature $60^{\circ} \mathrm{C}$, and extraction time $60 \mathrm{~min}$ ).

alkali solution $\mathrm{pH}$ value (e.g., extraction temperature $=60^{\circ} \mathrm{C}$ ) increased, the response value went up or down evidently, suggesting that the effect from interaction of extraction temperature and alkali solution $\mathrm{pH}$ value on saponin extraction rate was very significant. Similarly, Figures $7(b)$ and $7(c)$ showed that the interaction effects between extraction temperature and acid isolation $\mathrm{pH}$ value and between extraction 


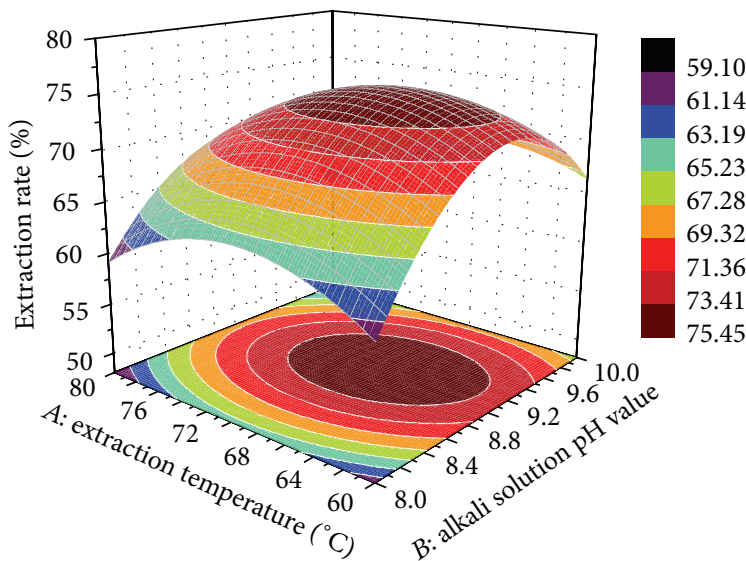

(a)

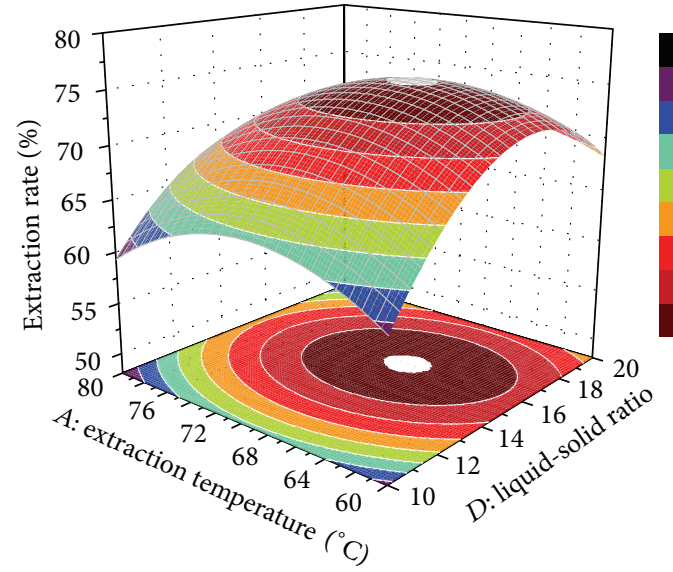

(c)

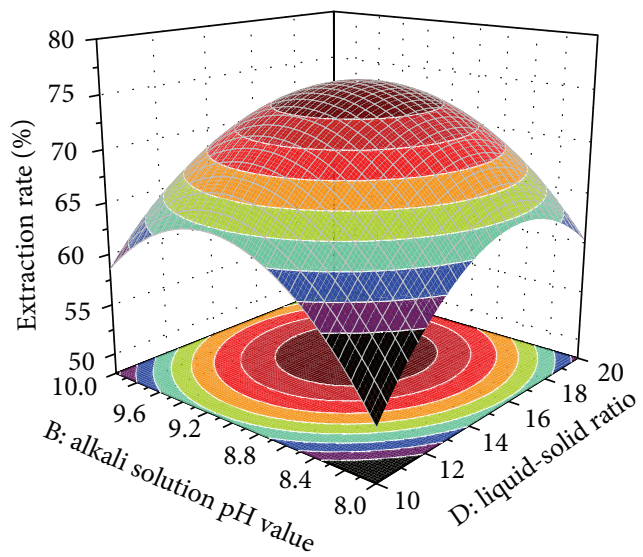

(e)
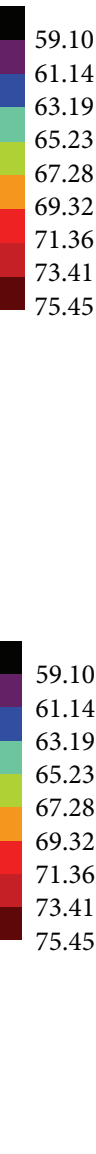

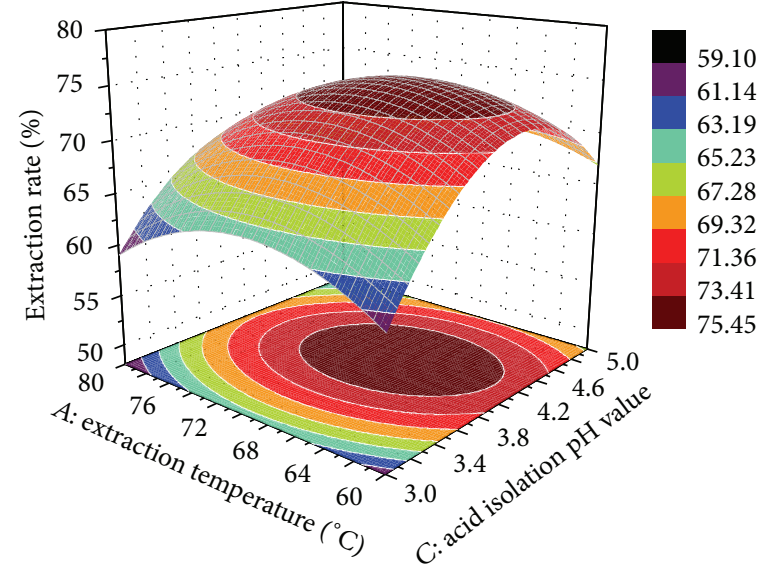

(b)

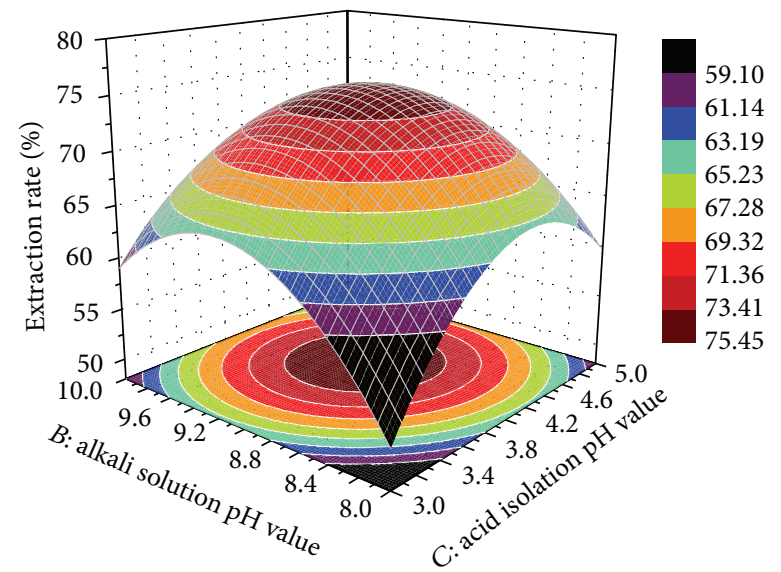

(d)

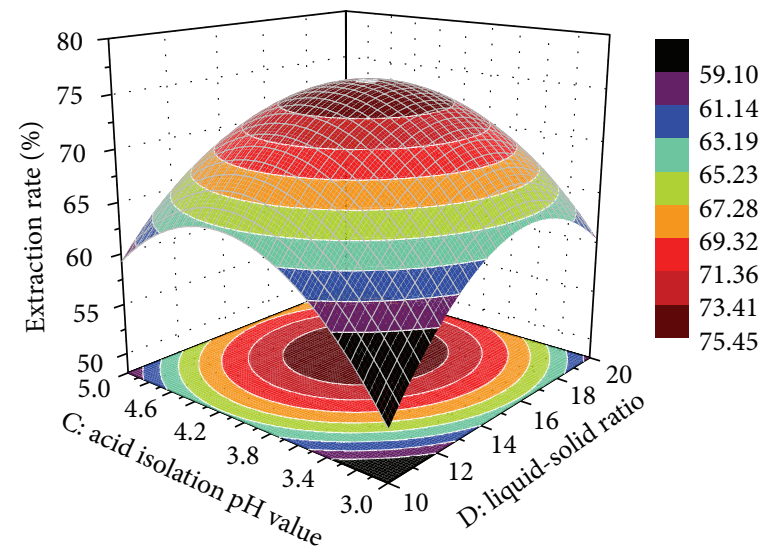

(f)

FIGURE 7: Corresponding response surfaces for extraction rate of saponin from Camellia oleifera cake. (a) Interaction effect between extraction temperature and alkali solution $\mathrm{pH}$ value on extraction rate of saponin; (b) interaction effect between extraction temperature and acid isolation $\mathrm{pH}$ value on extraction rate of saponin; (c) interaction effect between extraction temperature and liquid-solid ratio on extraction rate of saponin; (d) interaction effect between acid isolation $\mathrm{pH}$ value and alkali solution $\mathrm{pH}$ value on extraction rate of saponin; (e) interaction effect between alkali solution $\mathrm{pH}$ value and liquid-solid ratio on extraction rate of saponin; (f) interaction effect between acid isolation and liquid-solid ratio on extraction rate of saponin. 
temperature and liquid-solid ratio both were important for saponin extraction rate. Figures 7(d), 7(e), and 7(f) described the interaction effects between acid isolation $\mathrm{pH}$ value and alkali solution $\mathrm{pH}$ value, between alkali solution $\mathrm{pH}$ value and liquid-solid ratio, and between acid isolation $\mathrm{pH}$ value and liquid-solid ratio on the extraction rate of saponin, respectively. All of the response values changed gently, implying that the three interactions had no significant effects on the response.

Considering all responses mentioned above, the optimal extraction temperature, alkali solution $\mathrm{pH}$ value, acid isolation $\mathrm{pH}$ value, and liquid-solid ratio for obtaining saponin extraction rate were determined by ridge analysis. Extraction using a combination of extraction temperature $68^{\circ} \mathrm{C}$, alkali solution $\mathrm{pH}$ 9.1, acid isolation $\mathrm{pH} 4.1$, and liquid-solid ratio 15.9:1 provided an opportunity to obtain the maximal extraction rate of saponin from Camellia cake. The predicted optimal saponin extraction rate corresponding to these values was $75.79 \%$.

Three parallel replication experiments for verifying the predicting maximal extraction rate of saponin were performed under the above conditions. The result obtained by calculating the average of saponin extraction rate was $76.12 \%$, which was in close agreement with the predicting maximal extraction rate of saponin, confirming once more the suitability of the empirical model for quantitative predictions.

Compared with some findings of others, the combining method of alkali solution and acid isolation for tea saponin extraction has obvious advantages. For instance, Liu et al. [19] extracted tea saponin from oil-tea Camellia seed cake by a conventional ethyl alcohol technology. They obtained only an extraction rate of $15.99 \%$ under the optimal extraction conditions: extraction temperature $77.0^{\circ} \mathrm{C}$, extraction time $1.5 \mathrm{~h}$, and liquid -solid ratio $5: 1$. He et al. [6] recently reported an improved extraction method using microwave-assisted apparatus. Although the extraction time was reduced from $6 \mathrm{~h}$ to $4 \mathrm{~min}$ and organic solvent was saved by about $50 \%$, the processing craft was complex and the extraction yield was still very low (about 14\%). Alkali solution and acid isolation method is extensively applied to extract the proteins and flavonoids but rarely reported for tea saponin extraction. From the above results and discussion, it can be seen that the combination method has obvious advantages in relatively simple process, nonuse organic solvent, low cost, and so on.

\section{Conclusions}

The extraction process of saponin from Camellia cake was studied through a combining method of alkali solution and acid isolation, using the blend of sodium hydroxide and sodium tetraborate solution as an alkali buffer solution for protecting the saponin against destruction from alkali solution. This method can effectively improve the extraction rate of saponin and shorten the extraction time. In particular, no organic solvent was employed in the process of alkali solution and acid isolation, achieving low pollution and low cost. Process conditions for extraction saponin from Camellia cake were analyzed and successfully optimized by single-factor experiments and response surface methodology.
The effects of liquid-solid ratio, acid isolation $\mathrm{pH}$ value, alkali solution $\mathrm{pH}$ value, and extraction temperature on extraction rate of saponin from Camellia oleifera cake were significant. The influence order was the liquid-solid ratio $>$ acid isolation $\mathrm{pH}>$ alkali solution $\mathrm{pH}>$ extraction temperature. Optimized extraction conditions were as follows: extraction temperature $68^{\circ} \mathrm{C}$, alkali solution $\mathrm{pH} 9.1$, acid isolation $\mathrm{pH} 4.1$, and liquidsolid ratio $15.9: 1$. Under the optimum conditions, the optimal saponin ratio was $76.12 \%$.

\section{Conflict of Interests}

The authors declare that there is no conflict of interests regarding the publication of this paper.

\section{Acknowledgments}

The authors are grateful to the financial support by Science and Technology Planning Project of Quanzhou (2013Z23) and Science and Technology Planning Project of Fujian Province (2015J05026).

\section{References}

[1] J. Fu, X. H. Xia, L. Huang, N. M. Li, and X. D. Chen, "Development situation and prospects of oil-tea industry," Journal of Green Science and Technology, no. 10, pp. 147-149, 2015.

[2] J. S. Zhou, H. M. Liu, Q. Zhu, and Y. B. Zhou, "The comprehensive utilization of camellia oleifera seed," Academic Periodical of Farm Products Processing, vol. 7, pp. 19-26, 2006.

[3] Y.-F. Chen, C.-H. Yang, M.-S. Chang, Y.-P. Ciou, and Y.-C. Huang, "Foam properties and detergent abilities of the saponins from Camellia oleifera," International Journal of Molecular Sciences, vol. 11, no. 11, pp. 4417-4425, 2010.

[4] J. Zong, R. Wang, G. Bao et al., "Novel triterpenoid saponins from residual seed cake of Camellia oleifera Abel. show antiproliferative activity against tumor cells," Fitoterapia, vol. 104, pp. 7-13, 2015.

[5] S. Kijprayoon, V. Tolieng, A. Petsom, and C. Chaicharoenpong, "Molluscicidal activity of Camellia oleifera seed meal," ScienceAsia, vol. 40, no. 6, pp. 393-399, 2014.

[6] J. He, Z.-Y. Wu, S. Zhang et al., "Optimization of microwaveassisted extraction of tea saponin and its application on cleaning of historic silks," Journal of Surfactants and Detergents, vol. 17, no. 5, pp. 919-928, 2014.

[7] J.-L. Hu, S.-P. Nie, D.-F. Huang, C. Li, and M.-Y. Xie, "Extraction of saponin from Camellia oleifera cake and evaluation of its antioxidant activity," International Journal of Food Science and Technology, vol. 47, no. 8, pp. 1676-1687, 2012.

[8] L. Ma, Y. Z. Chen, S. F. Peng et al., "Study on extraction of tea saponin from Camellia oleifera cake using water as extraction solvent," Agricultural Science and Technology, vol. 16, no. 5, pp. 31-38, 2015.

[9] Z. Long and L. Tong, "The research on the extraction and purification technology of tea saponin," Guangzhou Chemical Industry, vol. 4, pp. 8-13, 2012.

[10] Y. Ye, Y. Li, and F. Fang, "Cost-effective isolation of bioactive compounds from a discarded bioresource-defatted seeds of Camellia oleifera," BioResources, vol. 10, no. 1, pp. 1060-1072, 2014. 
[11] S. Y. Zhang, X. Y. Cui, J. Shao, and Y. P. Han, "Optimization of extracting tea saponin from the cake of camellia seeds by orthogonal design," Journal of Southwest University for Nationalities (Natural Science Edition), vol. 5, pp. 25-30, 2009.

[12] Y. Q. Wu, "Application of foam separation technology to tea saponin extraction," Advanced Materials Research, vol. 997, pp. 173-177, 2014.

[13] J. Yan, Z. Wu, Y. Zhao, and C. Jiang, "Separation of tea saponin by two-stage foam fractionation," Separation and Purification Technology, vol. 80, no. 2, pp. 300-305, 2011.

[14] H. Deng, Y. Y. Tian, Z. Q. Tian, N. X. Qiu, and Y. R. Guo, "Study on the optimization of extraction processing for Xanthoceras sorbifolia bunge kernel protein by alkali-solution and acidisolation," Science and Technology of Food Industry, vol. 8, pp. 46-52, 2010.

[15] Y. Sun, Y. He, M. Gu, J. Chen, and F. Li, "Optimisation of the extraction conditions of natural colourant carthamin from safflower (Carthamus tinctorius L.) by response surface methodology," International Journal of Food Science \& Technology, vol. 49, no. 4, pp. 1168-1174, 2014.

[16] S. L. C. Ferreira, R. E. Bruns, H. S. Ferreira et al., "BoxBehnken design: an alternative for the optimization of analytical methods," Analytica Chimica Acta, vol. 597, no. 2, pp. 179-186, 2007.

[17] G. E. Box and K. Wilson, "On the experimental attainment of optimum conditions," Journal of the Royal Statistical Society Series B (Methodological), vol. 13, no. 1, pp. 1-45, 1951.

[18] R. H. Myers, D. C. Montgomery, and C. M. Anderson-Cook, Response Surface Methodology: Process and Product Optimization Using Designed Experiments, John Wiley \& Sons, New Jersey, NJ, USA, 3rd edition, 2009.

[19] B. P. Liu, C. X. Quan, X. B. Huang, Y. D. Chen, and Y. Zhang, "Optimization of ethanol extraction of tea saponin using response surface methodology," China Oils and Fats, vol. 38, no. 6, pp. 84-86, 2013. 

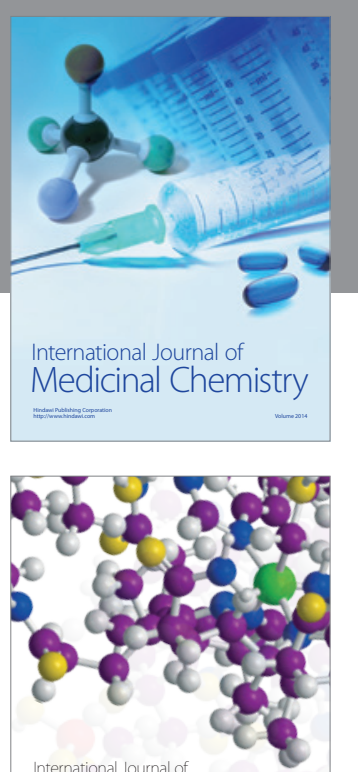

Carbohydrate Chemistry

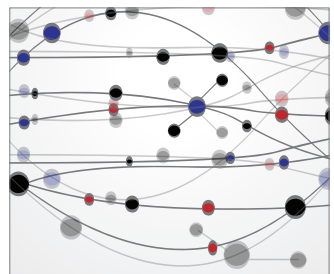

The Scientific World Journal
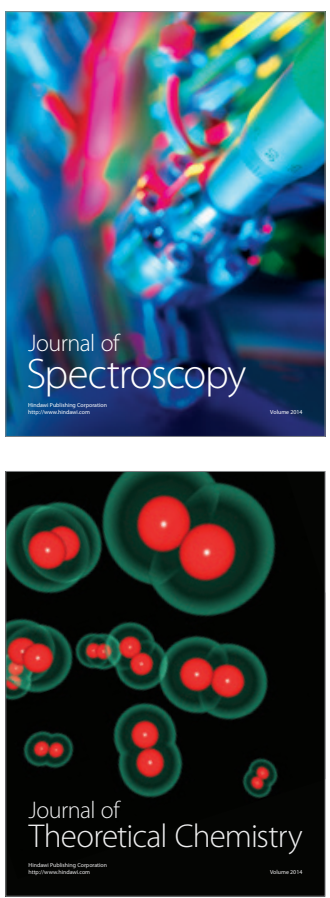
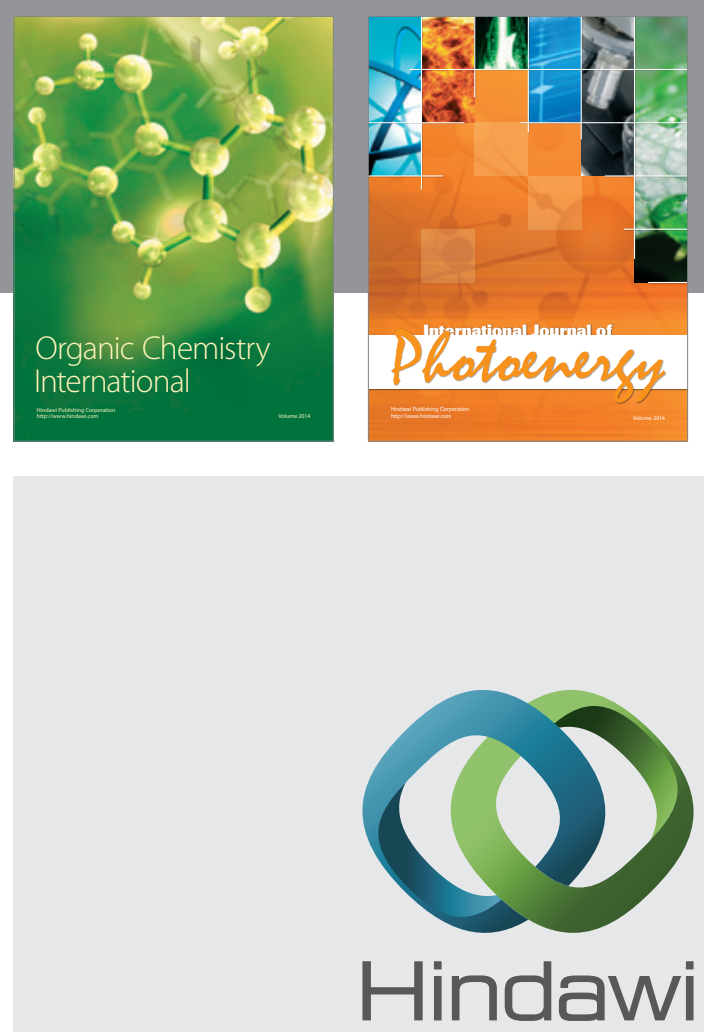

Submit your manuscripts at

http://www.hindawi.com

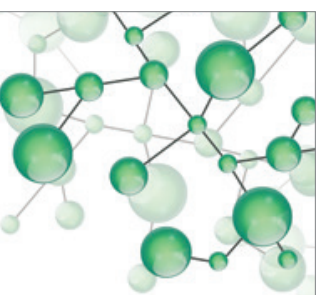

International Journal of

Inorganic Chemistry

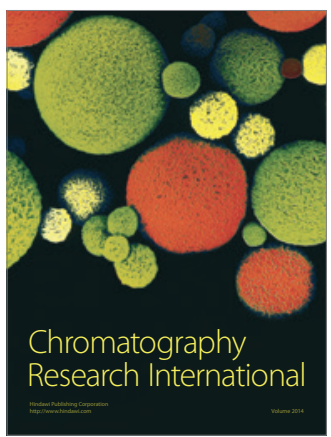

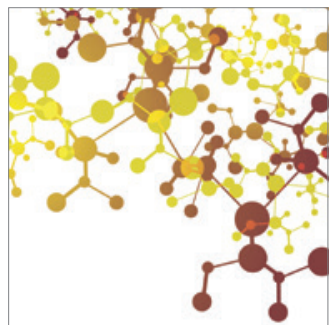

Applied Chemistry
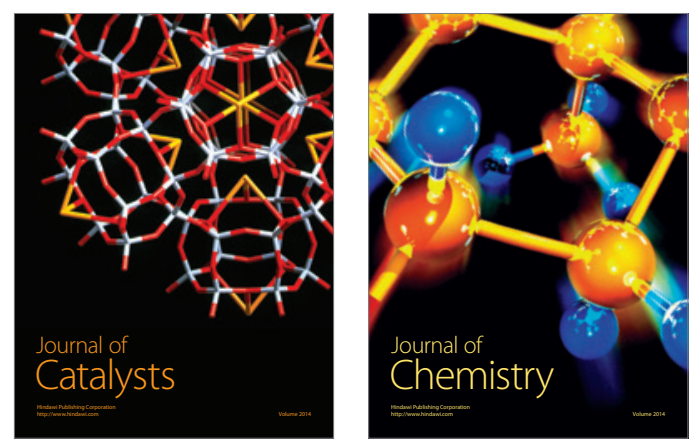
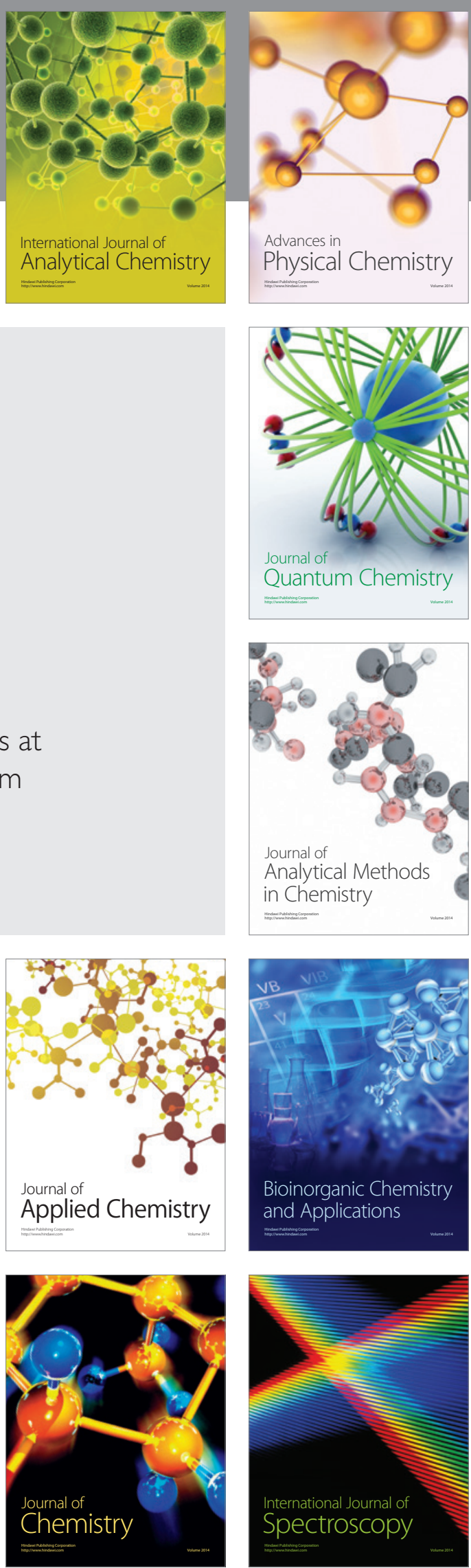